\title{
Effect of Steam Curing on Initial Strength Development of Mortar
}

\author{
Nozomi Nakajima, Takayoshi Maruyama, Hiromitsu Koyama, and Shigeyuki Date
}

\begin{abstract}
The steam curing process is being applied to produce precast concrete to accelerate production cycle. A prediction of initial strength is required to determine optimized production cycle and provide economical mix proportions. As for this, the strength estimate by the Maturity method is being used widely so far. However, this method is pointed that the accuracy of the estimated strength of the concrete which has been steam cured is low. This is one of the problems on the precast concrete production. In this study, the relationship between initial strength at early age and effective material age calculated by Maturity method and Arrhenius's law was evaluated. As a result, it showed a higher estimation accuracy of the Arrhenius's law than the Maturity method. However, the accuracy of the prediction was different in each condition such as cement type, water-cement ratio, and steam curing temperature and material age.
\end{abstract}

Index Terms-Arrhenius`s law, compressive strength, effective material age, maturity method, mortar, steam curing.

\section{INTRODUCTION}

The steam curing for precast concrete products often produce a lot of them in a short period of time [1]-[4]. The precast concrete product is managed in a factory and is made in good environment. Usually, the formwork of its production is once in a day. However, there are some cases which use the formwork twice a day to improve productivity. When using mold twice a day, it needs a steam curing at high temperature. Then, remove the mold at early age. And, it is necessary to predict strength of concrete at early age when it is demolded. In general, the Maturity method has been used for the strength prediction formula. To predict the initial strength of precast concrete products that are produced at the factory, it makes possible to determine removal time of the mold. In addition, strength prediction is important for the improvement of quality, safety and productivity.

Strength of concrete tends to increase with the material age and it also has high relation with the curing temperature. In addition, the reference temperature of the Maturity method is $-10{ }^{\circ} \mathrm{C}$ in Japan. However, there are some reports that $-10{ }^{\circ} \mathrm{C}$

Manuscript received December 5, 2016; revised April 1, 2017.

Nozomi Nakajima is with Tokai University of Civil Engineering, Japan (e-mail: hayabusa_ripobitann_0613@yahoo.co.jp)

Takayoshi Maruyama was with Tokai University of Civil Engineering. $\mathrm{He}$ is now with the Tsurumi concrete corporation, Department of Civil Engineering, Japan (e-mail: maruyama@tsuru-con.co.jp).

Hiromitsu Koyama was with Gunma University. He is now with the BASF Japan, Chigasaki Technical Development Center, Japan (e-mail: hiromitsu.koyama@basf.com).

Shigeyuki Date was with Nagasaki University. He is now with Tokai university as professor of Department of Civil Engineering, Japan (e-mail: sdat@tokai-u.jp) is not appropriate for the strength prediction of precast concrete products in early age. And it is also reported that to correct the initial material age is necessary in other references [5]. Strength development of the concrete depends on the curing temperature and curing time. Generally, in same mix proportion of the concrete, it is widely thought that the equivalent total Maturity value shows same compressive strength even in different maximum temperature. However, difference of the cement type is not concerned. If the cement type and curing temperature changes, hydration reaction rate will be different too. So, strength expression is also different. There is another formula called Arrhenius's law which represent compressive strength of concrete. Generally, ordinal chemical reaction rate depends on temperature of environment. Arrhenius's law represents the dependency of chemical reaction rate for temperature. In this case, Arrhenius's law is applied assuming the hydrating reaction of cement is kind of chemical reaction which its rate depends on temperature of environment. Thus, Maturity method and Arrhenius`s law have some formulas to calculate time (effective material age) which predict the predetermined strength expression of cementitious material [6].

In general, Maturity method is more popular for the prediction of strength expression than Arrhenius`s law. In many reports the Maturity method has been used to predict strength expression of concrete in early age. Especially study about prediction of strength expression of concrete under various temperature and concrete which received temperature history are reported with Maturity method in many cases. [7], [8]. However, there are no reports about the Maturity method for the concrete under the steam curing and prediction of strength expression using Arrhenius`s law [9]-[12].

Typically, it is thought that there is no difference of time to achieve equivalent compressive strength between formula of Maturity method and Arrhenius`s law. However, there are no reports and researches which proved difference between two of them comparatively so far. For example, relation between material age and compressive strength under various curing temperature of steam curing and so on.

In this study, the relation between curing time and compressive strength for the strength development time of both Arrhenius`s law and Maturity method were evaluated. Three patterns of curing condition and three kinds of cement were used.

\section{EXPERIMENTAL PROCEDURES}

\section{A. Materials}

Table I. shows materials used in this study. 3 kinds of 
cement such as Ordinary Portland cement (here in after "N"), furnace slag cement type B (here in after "BB") were used. High early strength Portland cement (here in after "H"), Blast

\begin{tabular}{|c|c|c|c|}
\hline \multirow{2}{*}{ Materials } & \multirow{2}{|c|}{ TABLE I: MATERIALS USED } & $\begin{array}{c}\text { Density } \\
\left(\mathrm{g} / \mathrm{cm}^{3}\right)\end{array}$ \\
\hline \multirow{3}{*}{ Cement } & Symbol & Properties & 3.16 \\
\hline & $\mathrm{N}$ & Ordinary Portland cement & 3.14 \\
\cline { 2 - 4 } & $\mathrm{H}$ & High-early-strength cement & 3.04 \\
\cline { 2 - 4 } & BB & Blast furnace slag cement type B & 2.69 \\
\hline Fine aggregate & S & River sand from Yamakitamati Kanagawa & - \\
\hline Chemical admixture & Ad & High-performance AE water reducing agent & \\
\hline
\end{tabular}

River sand from Yamakita city Kanagawa (here in after "S") was used for fine aggregate. Poly-carboxylic acid-based high-performance $\mathrm{AE}$ water reducing agent was used for chemical admixture.

\begin{tabular}{|c|c|c|c|c|}
\hline Type of cement & $\begin{array}{l}\mathrm{W} / \mathrm{C} \\
(\%)\end{array}$ & $\begin{array}{c}\mathrm{W} \\
\left(\mathrm{kg} / \mathrm{m}^{2}\right)\end{array}$ & $\underset{\left(\mathrm{kg} / \mathrm{m}^{2}\right)}{\mathrm{S}}$ & $\begin{array}{c}\mathrm{Ad} \\
(\mathrm{C} \times \%)\end{array}$ \\
\hline \multirow{3}{*}{$\mathrm{N}$} & 30 & \multirow{9}{*}{255} & 1168 & \multirow{3}{*}{$\mathrm{C} \times 0.7 \%$} \\
\hline & 40 & & 1350 & \\
\hline & 50 & & 1460 & \\
\hline \multirow{3}{*}{$\mathrm{H}$} & 30 & & 1163 & $\mathrm{C} \times 1.0 \%$ \\
\hline & 40 & & 1346 & \multirow{5}{*}{$\mathrm{C} \times 0.7 \%$} \\
\hline & 50 & & 1456 & \\
\hline \multirow{3}{*}{ BB } & 30 & & 1141 & \\
\hline & 40 & & 1330 & \\
\hline & 50 & & 1444 & \\
\hline
\end{tabular}

TABLE III: CONDITION OF EXPERIMENT

\begin{tabular}{|c|c|c|c|}
\hline $\begin{array}{l}\text { Type of } \\
\text { cement }\end{array}$ & $\begin{array}{l}\text { W/C } \\
(\%)\end{array}$ & $\begin{array}{c}\text { Curing } \\
\text { temperature }\end{array}$ & Pattern \\
\hline \multirow{9}{*}{$\mathrm{N}$} & 30 & \multirow{3}{*}{10} & N-30-10 \\
\hline & 40 & & $\mathrm{~N}-40-10$ \\
\hline & 50 & & N-50-10 \\
\hline & 30 & \multirow{3}{*}{20} & $\mathrm{~N}-30-20$ \\
\hline & 40 & & $\mathrm{~N}-40-20$ \\
\hline & 50 & & $\mathrm{~N}-50-20$ \\
\hline & 30 & \multirow{3}{*}{40} & $\mathrm{~N}-30-40$ \\
\hline & 40 & & N-40-40 \\
\hline & 50 & & N-50-40 \\
\hline \multirow{6}{*}{$\mathrm{H}$} & 30 & \multirow{3}{*}{20} & H-30-20 \\
\hline & 40 & & H-40-20 \\
\hline & 50 & & H-50-20 \\
\hline & 30 & \multirow{3}{*}{40} & H-30-40 \\
\hline & 40 & & H-40-40 \\
\hline & 50 & & H-50-40 \\
\hline \multirow{6}{*}{ BB } & 30 & \multirow{3}{*}{20} & BB-30-20 \\
\hline & 40 & & BB-40-20 \\
\hline & 50 & & BB-50-20 \\
\hline & 30 & \multirow{3}{*}{40} & BB-30-40 \\
\hline & 40 & & BB-40-40 \\
\hline & 50 & & BB-50-40 \\
\hline
\end{tabular}

TABLE IV: CURING CONDITION

\begin{tabular}{|c|c|c|}
\hline $\begin{array}{c}\text { W/C } \\
(\%)\end{array}$ & $\begin{array}{c}\text { Curing } \\
\text { temperature } \\
\left({ }^{\circ} \mathrm{C}\right)\end{array}$ & $\begin{array}{c}\text { Material age } \\
\text { (hour) }\end{array}$ \\
\hline \multirow{3}{*}{$30,40,50$} & 10 & $69,96,192,384$ \\
\cline { 2 - 3 } & 20 & $32,48,96,192$ \\
\cline { 2 - 3 } & 40 & $8,12,14,24,48,96$ \\
\hline
\end{tabular}

\section{B. Mix Proportions}

Table II shows mix proportions of fresh mortar. The value of unit water was set as $255 \mathrm{~kg} / \mathrm{m}^{3}$ which suppose the unit water of normal strength concrete (i.e. $\mathrm{W}=160 \mathrm{~kg} / \mathrm{m}^{3}$ ). $30 \%$, $40 \%, 50 \%$ of water cement issue were set for each type of cement. Dosage of admixture was determined to achieve 150 to $200 \mathrm{~mm}$ of flow value of fresh mortar. The combinations of the experiment are shown in Table III. Two or three patterns of steam curing temperature were set for each mix proportions, totally 21 patterns of combination were evaluated in this study.

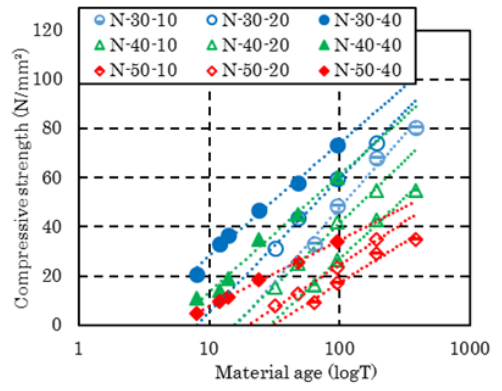

Fig. 1. Relation between material age and compressive strength $(\mathrm{N})$.

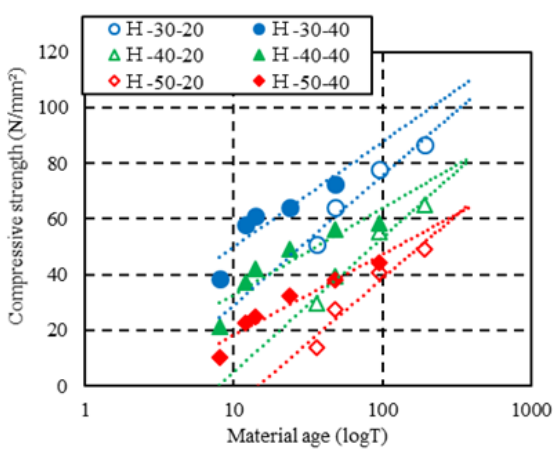

Fig. 2. Relation between material age and compressive strength $(\mathrm{H})$.

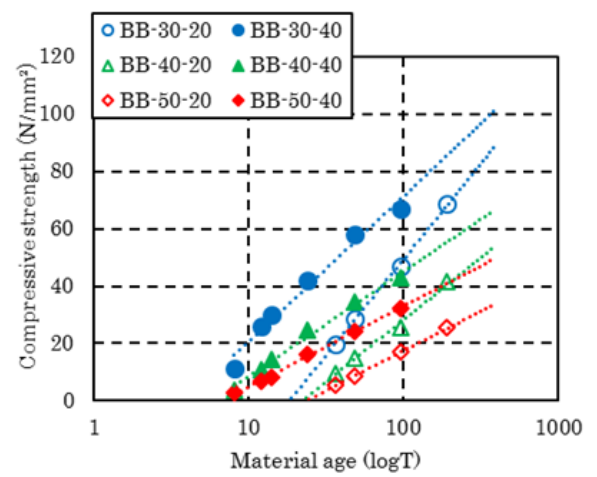

Fig. 3. Relation between material age and compressive strength (BB).

\section{OUTLINE OF EXPERIMENT}

\section{A. The Combination of Curing Condition}

Before mixing, fine aggregate and cement were kept at predetermined temperature same as curing temperature. Further, since the curing temperature is constant, temperature 
rising and temperature falling is not set.

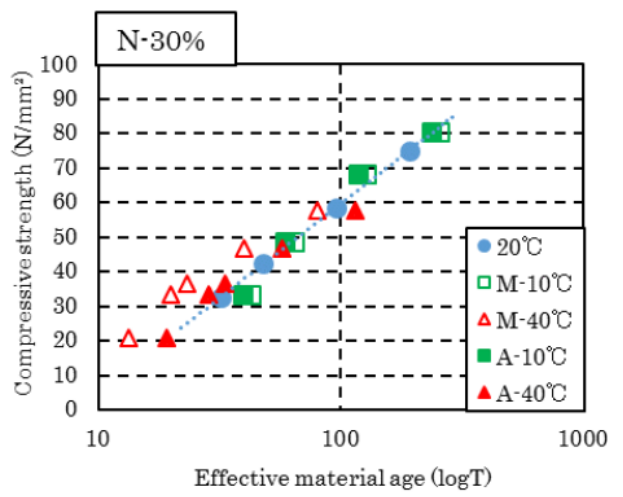

Fig. 4. Relation between effective material age and compressive strength $(\mathrm{N}-30 \%)$.

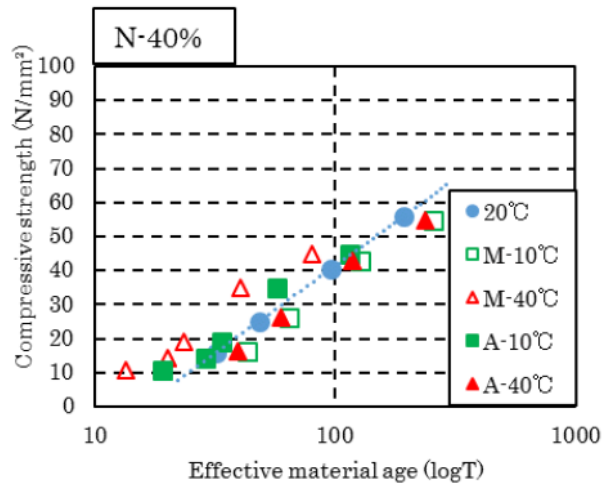

Fig. 5. Relation between effective material age and compressive strength $(\mathrm{N}-40 \%)$.

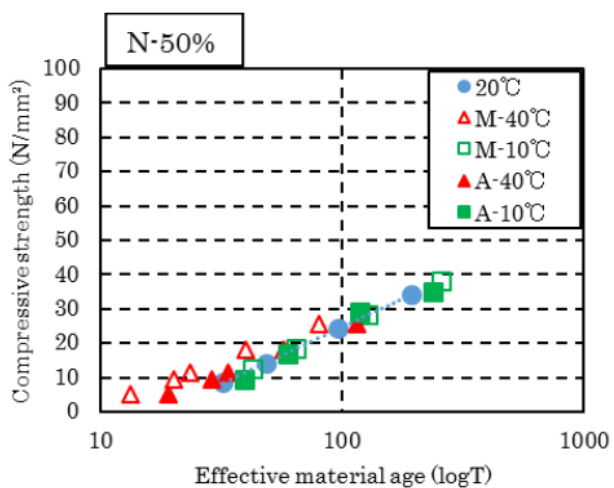

Fig. 6. Relation between effective material age and compressive strength $(\mathrm{N}-50 \%)$.

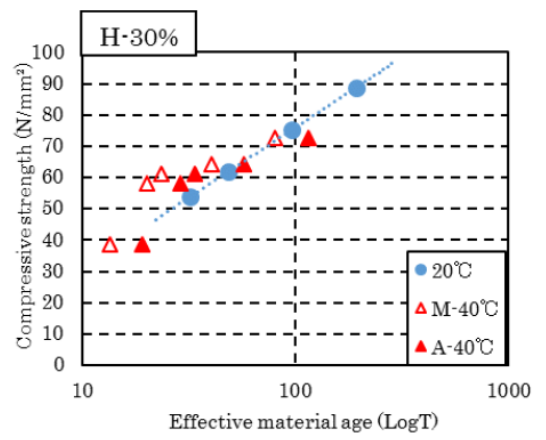

Fig. 7. Relation between effective material age and compressive strength $(\mathrm{H}-30 \%)$.

\section{B. Test Items}

Compressive strength was mainly measured in this experiment using specimens which sized $\varphi 50 \times 100$. Table IV shows the material age of specimen for each different curing temperature for compressive test.

\section{Prediction Method of Strength Development}

1) Effective material age formula based on the Maturity method

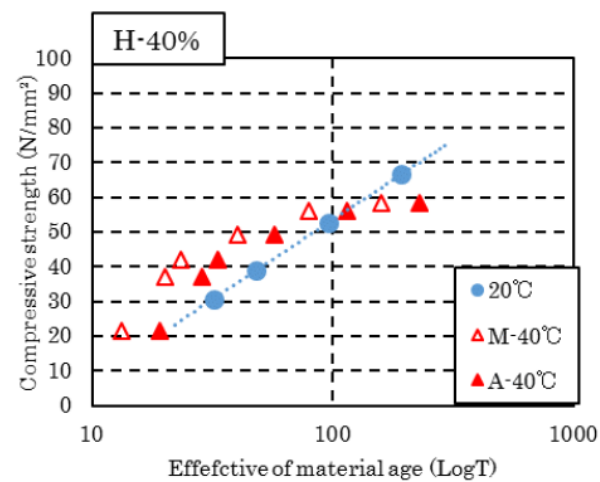

Fig. 8. Relation between effective material age and compressive strength (H-40\%)

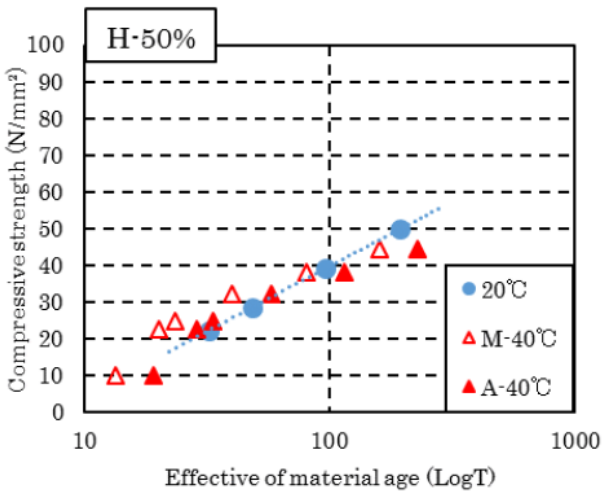

Fig. 9. Relation between effective material age and compressive strength (H-50\%).

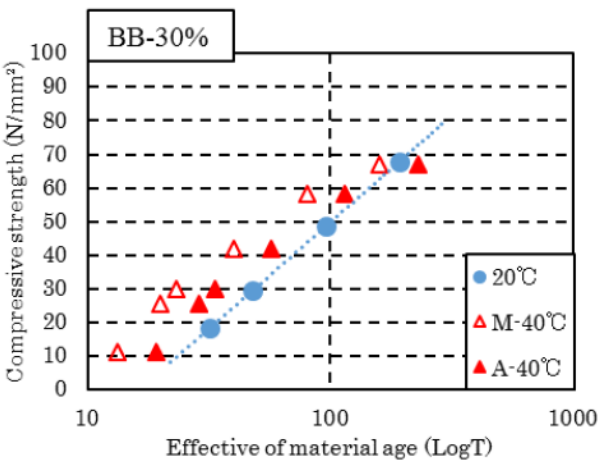

Fig. 10. Relation between effective material age and compressive strength (BB-30\%).

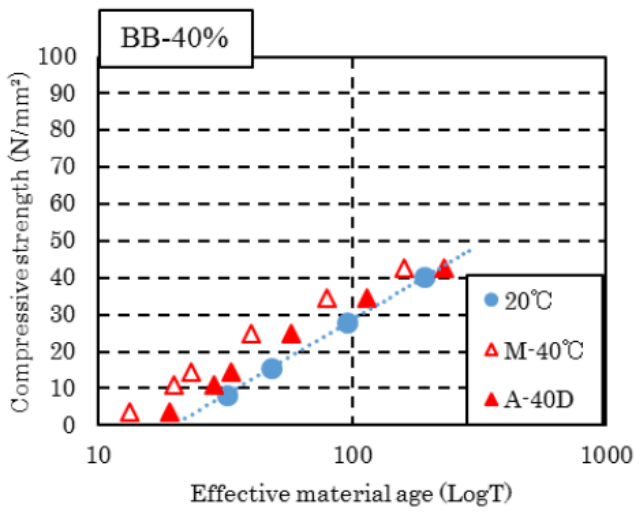

Fig. 11. Relation between effective material age and compressive strength (BB-40\%). 


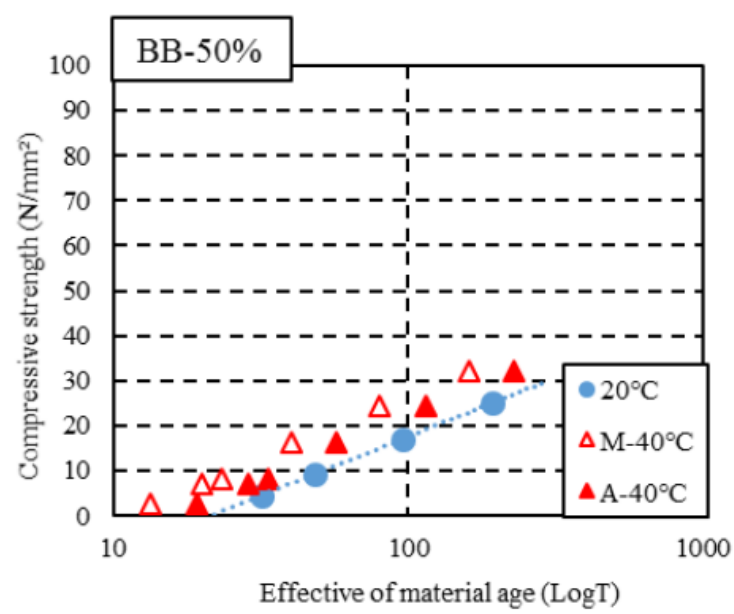

Fig. 12. Relation between effective material age and compressive strength (BB-50\%)

Using the Maturity method, which is commonly known as a prediction formula of strength expression. In this study using the Maturity method, evaluation was made for compressive strength in short term material age from the initial material age of mortar under steam curing [13], [14].

$$
M=\int_{0}^{t}\left(T_{k}+10\right) d t
$$

Here, M: accumulated temperature $\left[{ }^{\circ} \mathrm{C} \cdot\right.$ hour$]$

Tk: concrete temperature $\left[{ }^{\circ} \mathrm{C}\right]$

$\Delta \mathrm{t}$ : curing time [hour]

\section{Effective Material Age}

Effective material age is believed to be useful for evaluating the mechanical characteristics of the hardened cement body subjected to Non-steady-state temperature history. The generally effective material age, the influence of the curing temperature on the hydration reaction shows a material age converted to curing temperature is degree of hydration equivalent to the time of $20^{\circ} \mathrm{C}$.

In this study, it was evaluated for effective material age applicability with an effective material age (te), which has already been proposed. The following shows the existing valid material age calculation formula.

\section{1) Effective material age formula (1)}

Effective material age formula (1) is a rule of thumb that is calculated based on a Maturity method by the constant for values of the accumulated temperature method. So, effective material age formula (1) and Maturity method is the same trend. Therefore, consideration of a Maturity-method in this study will be omitted and it was decided to consider as a representative of the effective material age (1) formula shown in (2) formula.

$$
t_{e}=\int_{0}^{t} \frac{\left(T_{k}+10\right)}{30} d t
$$

\section{2) The effective material age formula (2)}

The formula of effective material age (2) have a relationship to the temperature dependence of the hydration reaction of concrete. It is also expressed per Arrhenius`s law.
However, for the calculation of activation energy (Uh), it has been some reports various studies, including the experimental study to until now. (3) Formula is calculated, crack control guidelines Standard Specification for Concrete Structures and mass concrete, and the formula in consideration of practicality adopted in fib Model Code2010, derived by assuming an activation energy $33 \mathrm{~kJ} / \mathrm{mol}$ it is an expression [15]- [17].

$$
t_{e}=\int_{0}^{t} \exp \left\lfloor 13.65-\frac{4000}{273+T_{k}}\right\rfloor d t
$$

\section{RESULTS AND DISCUSSION}

\section{A. Compressive Strength Results}

Relation between material age and compressive strength of each different cement is shown in Fig. 1, Fig. 2, and Fig. 3. Compressive strength of mortar showed larger strength in higher curing temperature on all types of cement. Focusing on strength enhancement ratio, mortar which cured in lower temperature showed smaller strength enhancement ratio. It will be possible mortar which cured in low temperature to reach to equivalent compressive strength as high temperature cured mortar after a long time. Then focusing on type of cement, $\mathrm{H}$ cement showed the largest compressive strength and $\mathrm{BB}$ cement showed the lowest compressive strength, also lower water cement ratio showed larger strength for equivalent material age as same as normal curing.

\section{General Versatility of the Effective Material Age Calculation Formula of Strength Estimation}

An effective material age formula (1) of accumulated temperature method and the Arrhenius law effective material age formula (2) of effective material age and compressive strength, which is calculated from the type relationship shown in Fig. 4 to Fig. 6. Maturity method and the Arrhenius law is not the difference between the effective material age of $20{ }^{\circ} \mathrm{C}$ curing because they both set the reference temperature and $20{ }^{\circ} \mathrm{C}$. The real strength at $20{ }^{\circ} \mathrm{C}$, to calculate the effective material age from the Maturity method $\sigma=a^{*} \log \mathrm{Te}+\mathrm{b}$ and the Arrhenius law to create a regression line $(\sigma=a \log \mathrm{Te}+\mathrm{b})$. In data obtained at the reference temperature $20{ }^{\circ} \mathrm{C}$ to calculate the $\sigma=\operatorname{alog} \mathrm{Te}+\mathrm{b}$ equation in the case the temperature is the same even when the effective material age will change the measured value is overlapped on the regression line. In addition, if the temperature is different to modify the effective material age on the basis of the effective material age formula. At that time, when substituting the effective material age to $\sigma$ $=\mathrm{alog} \mathrm{Te}+\mathrm{b}$ estimated strength was corrected for the case where the temperature is different is close to the measured value, the scope of application of the effective material age equation it can be seen that wide. Furthermore, the scope of application of the effective material age equation for the case of the estrangement between the actual measurement value is large, it can be seen that can be applied narrowly only constant temperature. Therefore, the closer to the regression line of reference temperature $20{ }^{\circ} \mathrm{C}$, and other high precision of estimated strength than the curing temperature, it can be 
said that there is a high versatility.

When comparing the results of the Maturity method and the Arrhenius law, Maturity-method in all cases is away from the regression line, and result obtained by the Arrhenius law has become a result close to the regression line. Therefore, Arrhenius law can be said to higher general versatility than the Maturity method. In addition, focus on the Early Age of Fig. 4 to Fig. 6. Early Age Point is a large estrangement from the regression line, estrangement from the regressionline is small in the long-term material age. It can be seen that the estimation accuracy is not fit even in the Arrhenius law at the young age material from the above.

Next, let us focus on W / C and Arrhenius law. According to the value of $\mathrm{W} / \mathrm{C}$ increases, the result of the Arrhenius law is away from the regression line. It can be said versatility is low greatly when the value of $\mathrm{W} / \mathrm{C}$ is increase. Since in the type of cement away from the regression line in the High early strength cement $>$ Ordinary Portland cement > Blast slag type $\mathrm{B}$ of order of things, the estimation accuracy of the strength can be said to be low compared to other cement of Fig. 4 to 12.

\section{Accuracy of Estimation for Compressive Strength}

Through all results, estimated strength becomes higher than measured compressive strength when the stream curing temperature was higher, that means kind of overestimating of performance. On the other hand, estimated strength becomes smaller than measured compressive strength when the steam curing temperature was lower in this time.

\section{CONCLUSION}

In this study, the effects of curing temperature on the Maturity method and Arrhenius's law were investigated compatibility between the accumulated temperature and effective material age. What we obtained through this research are below.

1) For the accuracy of estimation through Maturity method and Arrhenius`s law, the Arrhenius`s law showed higher accuracy than Maturity method to predict compressive strength of mortar.

2) The accuracy of estimation accuracy for compressive strength based on effective material age, focusing on type of cement, $\mathrm{H}$ cement showed the largest estimation accuracy of compressive strength, and BB cement showed lowest estimation accuracy on compressive strength. Especially, it showed higher estimation accuracy when the material age got longer.

3) In the case of higher water cement ratio, the estimation accuracy of compressive strength got lower in each temperature of steam curing.

4) On the strength estimation based on effective material age, the estimation accuracy got worth when the curing temperature got leaves largely from $20^{\circ} \mathrm{C}$.

This time, data which measured was not fully completed. It is usual to apply steam curing at higher temperature than this study such as $60^{\circ} \mathrm{C}$ at factory. For future study, it has already been planned to evaluate performance and relation between effective material age and compressive strength of mortar and concrete which received steam curing at high temperature such as $60^{\circ} \mathrm{C}$. On the other hand, it also should be known about the case which curing temperature was extremely low such as $10^{\circ} \mathrm{C}$.

\section{ACKNOWLEDGMENT}

This research was supported by the Tsurumi Concrete corporation and BASF Japan Ltd.

\section{REFERENCES}

[1] R. W. Nurse, "Steam curing of concrete," Magazine of Concrete Research, vol. 1, no. 2, pp. 79-88, June 1949.

[2] A. G. A. Saul, "Principles underlying the steam curing of concrete at atmospheric pressure," Magazine of Concrete Research, vol. 2, no. 6, pp. 127-140, March 1951.

[3] E. C. Higginson, "Effect of steam curing on the important properties of concrete," Journal Proceedings, vol. 58, no. 9, pp. 281-298, September 1961

[4] S. Tqrkela and V. Alabasb, "The effect of excessive steam curing on Portland composite," Cement and Concrete Research, vol. 35, no. 2, pp. 405-411, February 2005.

[5] Y. Kasai, K. Yokoyama, and T. Hiraga, "Initial Strength of Concrete," Transactions of the Architectural Institute of Japan, vol. 16, pp. 255-259, 1962.

[6] G. Chanvillard and L. D'aloia, "Concrete strength estimation at early ages: Modification of the method of equivalent age," ACI Materials Journal, vol. 94, no. 6, pp. 520-530, 1997.

[7] R. W. Barnes, A. K. Schindler, M. L. Hughes, and S. L. McFarland, "Evaluation of the maturity method to estimate concrete strength," Highway Research Center and Department of Civil Engineering at Auburn University, 2006

[8] C. K. Volz, R. L. Tucker, N. H. Burns, and H. S. Lew "Maturity effects on concrete strength," Cement and Concrete Research, vol. 11, no. 1, pp. 41-50, January 1981,

[9] M. Azenha, R. Faria, and D. Ferreira, "Identification of early-age concrete temperatures and strains: Monitoring and numerical simulation," Cement and Concrete Research, vol. 31, no. 6, pp. 369-378, July 2009.

[10] N. J. Carino and R. C. Tank, "Maturity function for concretes made with various cements and admixtures," Materials Journal, vol. 89, no. 2, pp.188-196, March 1992

[11] C. J. Guo, "Maturity of concrete: Method for predicting early-stage strength," Materials Journal, vol. 86, no. 4, pp. 341-353, July 1989.

[12] J. K. Kim, Y. H. Moon, and S. H. Eo, "Compressive strength development of concrete with different curing time and temperature," Cement and Concrete Research, vol. 28, no. 12, pp.1761-1773, December 1998.

[13] Yahia A. Abdel-Jawad, "The maturity method: Modifications to improve estimation of concrete strength at later ages," Construction and Building Materials, vol. 20, no. 10, pp .893-900, December 2006

[14] ASTM C1074 (Cement Standards and Concrete Standards) "ASTM C 1074-11: Standard practice for estimating concrete strength by the maturity method," 2001

[15] A. V. Saetta, B. A. Schrefler, and R. V. Vitaliani, "The carbonation of concrete and the mechanism of moisture, heat and carbon dioxide flow through porous materials," Cement and Concrete Research, vol. 23, no. 4, pp.761-772, July 1993

[16] H. Kada-Benameura, E. Wirquina, and B. Duthoita, "Determination of apparent activation energy of concrete by isothermal calorimetry," Cement and Concrete Research, vol. 30, no. 2, pp. 301-305, February 2000.

[17] L. D'Aloia and G. Chanvillard, "Determining the "apparent" activation energy of concrete: Ea-numerical simulations of the heat of hydration of cement," Cement and Concrete Research, vol. 32, no. 8, pp.2377-1289, August 2002.

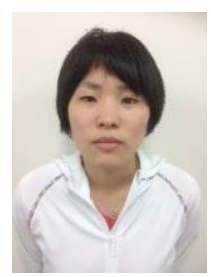

Nozomi Nakajima was born in Tokyo prefecture on April 3, 1992. She graduated bachelor degree of civil engineering course in Tokai University, Hiratsuka city, Japan in March 2016. Now she is a candidate of master course of civil engineering course of Tokai University. Her research interests are about engineering of precast concrete.

She is a member of JSCE and JCI. 


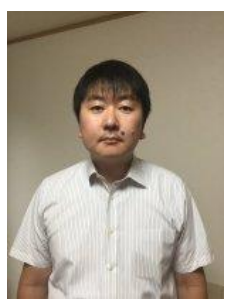

Takayoshi Maruyama was born in Kanagawa prefecture on July 27, 1978. He graduated bachelor degree of civil engineering course in Tokai University, Hiratsuka city, Japan in March 2001. Now he is working for Turumi Concrete. Tokai University. His research interests are about engineering of precast concrete.

He is a member of JSCE and JCI.

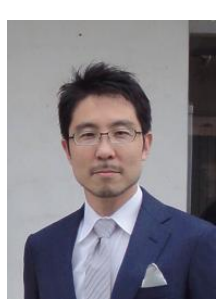

Hiromitsu Koyama was born in Gunma prefecture Japan. He has completed graduate school of Gunma University in 1999. He is currently researcher of concrete admixture in BASF Japan Ltd. His current and previous research interests are Productivity Improvement of Precast Concrete and Tunnel Lining Concrete.

He is a member of JCI, JSCE and JPCI.

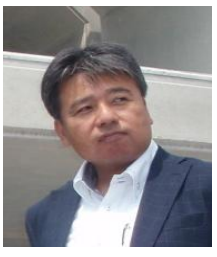

Shigeyuki Date was born in Fukuoka prefecture Japan. Graduated from Nagasaki University as professor of Department of Civil Engineering, 4-1-1 Kitakaname Hiratuka Kanagawa Japan. Current and previous research interests are Material design, Durability of Concrete structure, Concrete production, and Precast Concrete.

S. Date, et al., "The evaluation of norm (EN 1504-2)," Concrete Engineering, vol.50, no.4, pp331-337, April. 2012. $\mathrm{He}$ is a member of JCI, AIJ, SMSJ. 